\title{
Regio- and stereo-specific chemical depolymerization of high molec- ular weight polybutadiene and polyisoprene for their analysis by high resolution FTICR mass spectrometry. Comparison with Py- GCXGC-MS, ASAP \& DIP-APCI MS and IMS-MS
}

\section{Ziad Mahmoud, ${ }^{\dagger}$ Fabrice Bray, ${ }^{\dagger}$ Marie Hubert-Roux, ${ }^{\ddagger}$ Michel Sablier, ${ }^{\S}$ Carlos Afonso, ${ }^{\ddagger}$ and Christian Rolando ${ }^{+, *}$}

\author{
† Univ. Lille, CNRS, USR 3290, MSAP, Miniaturisation pour la Synthèse l'Analyse et la Protéomique, F-59 000 Lille, \\ France \\ \$ Normandie Université, Université de Rouen, UMR 6014, CNRS, COBRA, Chimie organique et bioorganique, Réactivité et \\ Analyse, 76821 Mont-Saint-Aignan Cedex, France \\ $\S$ Muséum National d'Histoire Naturelle, USR 3224, CNRS, Centre de Recherche sur la Conservation, 36, rue Geoffroy \\ Saint-Hilaire, 75005 Paris
}

\begin{abstract}
:
Polybutadiene (PB) and Polyisoprene (PI) the two most common polydienes (PD), are involved in a large number of materials and used in a wide variety of applications. The characterization of these polymers by mass spectrometry (MS) continues to be very challenging due to their high insolubility and the difficulty to ionize them. In this work, cross-metathesis reaction was used to generate end-functionalized acetoxy ionizable oligomers for the structural deciphering of different commercial PB and PI samples. A crossmetathesis reaction was carried out between polymers and the Z-1,4-diacetoxy-2-butene as chain transfer agent in dichloromethane using Hoveyda-Grubbs second-generation catalyst. Well-defined acetoxy telechelic structures were obtained and analysed by FourierTransform ion cyclotron resonance (FTICR) high resolution MS. However, after depolymerization, low molar mass polyolefins contained some units with different configurations, suggesting an olefin isomerization reaction due to the decomposition of the catalyst. The addition of an electron-deficient reagent such as 2,6-dichloro-1,4-benzoquinone suppressed this isomerization in the case of both $Z$ - and E-PB and PI. Ion-mobility spectrometry-mass spectrometry (IMS-MS) and Energy resolved tandem mass spectrometry (ERMS) analyses confirmed a successful isomerization suppression. For comparing the results obtained by depolymerisation with classical methods for polymer analysis, pyrolysis-comprehensive two-dimensional gas chromatography/mass spectrometry (PyGC $\times$ GC-MS), atmospheric solid analysis probe (ASAP) and direct inlet probe-atmospheric pressure chemical ionization (DIP-APCI) analyses were performed on the same polymers. This strategy can be applied on a variety of synthetic and natural not yet characterized polymers.

Keywords: polydienes: polybutadiene (PB), polyisoprene (PI); chemical depolymerization; FTICR high resolution mass spectrometry; ASAP, DIP-APCI, Py-GC $\times$ GC-MS
\end{abstract}

Polyolefins, such as polybutadiene (PB) and polyisoprene (PI) are among the most commonly used polymers in a large number of materials ranging from simple products to more complex applications such as plastics and medical supplies. In recent years, interest has grown dramatically in these versatile macromolecules which increased the necessity to elucidate their structure and to follow their degradation mechanism. ${ }^{1}$

The classical methods for PD studies by mass spectrometry is based on pyrolysis. ${ }^{2}$ The first method consists on using pyrolysis-comprehensive two-dimensional gas chromatography/mass spectrometry (Py-GC $\times$ GC-MS). It is well known that $1 \mathrm{D} \mathrm{GC}$ is a powerful analytical technique able to separate hundreds of peaks at a time. However, when it comes to complex mixtures and polymers, the addition of a second dimension is required. This is achieved by connecting two capillary columns via a modulation system and using a mass spectrometer as a detector giving rise to a very powerful analytical tool, the $\mathrm{GC} \times \mathrm{GC} / \mathrm{MS}$. Analysing polymers with $\mathrm{Py}-\mathrm{GC} \times \mathrm{GC}-\mathrm{MS}$ system does not require sample preparation and offers many advantages such as higher resolution, peak separation capacity and selectivity. ${ }^{3}$

More recently Atmospheric solid analysis probe (ASAP) has been developed by McEwen, ${ }^{4,5}$ and proved to be an efficient method for the rapid analysis of solid materials using a heated nitrogen desolvation gas to vaporize the sample and a corona discharge for ionization. It is capable of ionizing low polarity compounds not amenable to ESI without the need to any sample preparation steps and it is compatible with ion-mobility mass spectrometry (IMS) which reveals minority constituents. However, the complex mixtures produced by ASAP are better analysed by very high-resolution spectrometers such as Fourier transform ion cyclotron resonance (FT-ICR) mass spectrometer which allows to differentiate between isobaric species and attribute each signal with a unique elemental composition. ${ }^{6}$ Conveniently, FT-ICR MS are generally fitted with direct inlet probe-atmospheric pressure chemical ionization (DIP-APCI) sources, the principle of which is similar to that of ASAP source. DIP-APCI was used to characterize copolymer blends, cross-linked copolymers and additives. ${ }^{7,8}$

On the other hand, electrospray ionization source (ESI-MS) is still not well optimized yet for the PD analysis due to their high insolubility in ESI-compatible solvents, their electroneutrality and difficulty to be cationized and their high molecular mass which prohibits their ionization by the ESI mechanism. ${ }^{9}$. The important role of PD as a base for the preparation of more advanced polymeric materials imposes the development of new soft techniques for improving their ionization and by consequence their analysis. 
In a first step, we developed here a new strategy based on the cross-metathesis reaction of PB and PI using Hoveyda-Grubbs organometallic catalyst which allows to solubilize the polymers and to generate end-functionalized acetoxy oligomers ionisable by ESI for the characterization of PB and PI in both $E$ and $Z$ configurations. Ion mobility mass spectrometry (IMS-MS) showed that under classical cross-metathesis conditions, the oligomers were isomerized. We successfully suppressed this isomerization during olefin metathesis by adding a hydride scavenger as shown by IMS-MS and energy resolved mass spectrometry (ER-MS). Finally, for comparison we performed classical pyrolysis techniques such as $\mathrm{Py} / \mathrm{GC} \times \mathrm{GC}-\mathrm{MS}$ and atmospheric ionization sources such as ASAP and DIP-APCI coupled to ion-mobility mass spectrometry and Fourier transform high-resolution mass spectrometry. High resolution MS allowed to attribute the elemental composition of the obtained pyrolysis products and distributions. These results are compared with those from the cross-metathesis reaction and ESI analysis.
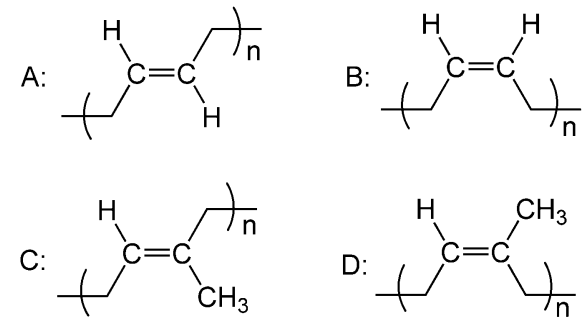

Figure 1. A: E-PB, B: Z-PB, C: E-PI, D: Z-PI

\section{EXPERIMENTAL}

Samples. Two samples of PB and two samples of PI were used in this study. Z-PB (1,4-PB; 98\% Z; Mw 200,000-300,000 g. $\left.\mathrm{mol}^{-1}\right)$ and $E$-PB $(1,4-\mathrm{PB} ; 36 \% \mathrm{Z} ; 55 \% \mathrm{E}$; Mw 200 000 g.mol $\left.{ }^{1}\right)$; Z-PI (1,4-PI; $98 \%$ Z; Mw 38 000 g.mol $\left.{ }^{-1}\right)$ and $E$-PI (1,4-PI; 99\% E; Mw 35 000 g. $\mathrm{mol}^{-1}$ ) were purchased from Sigma-Aldrich and used as received. (Z)-1,4-diacetoxy-2-butene (95\%); 2,6-dichloro-1,4-benzoquinone $(98 \%)$ and (1,3-Bis-(2,4,6-trimethylphenyl)-2-imidazolidinylidene) dichloro(o-isopropoxyphenylmethylene) ruthenium (Hoveyda-Grubbs second generation catalyst; $97 \%$; $\mathrm{Mw} 626.62$ g. $\mathrm{mol}^{-1}$ ) were purchased from Sigma-Aldrich and used as received. Lithium- ${ }^{7} \mathrm{Li}$ chloride, Methanol and Dichloromethane (anhydrous; $\geq 99.8 \%$ ) were also obtained from Sigma-Aldrich and used without further purification.

PB \& PI cross-metathesis. All experiments were conducted in Schlenk tubes in an atmosphere of dry nitrogen. Either the $Z$ - or the $E$ - polymer $\left(25 \mathrm{mg}, \mathrm{Mw} \sim 200000 \mathrm{~g} . \mathrm{mol}^{-1}, 0.125 \mu \mathrm{mol}\right)$ were first introduced in a Schlenk tube. A prepared solution containing the chain transfer agent $(Z)-1,4$-diacetoxy-2-butene $(10 \mu \mathrm{L}$, $[\mathrm{CTA}] /[\mathrm{PB}]=500)$ and the Hoveyda-Grubbs second generation catalyst $(1.5 \mathrm{mg},[$ Catalyst $] /[\mathrm{PB}]=20)$ dissolved in $1 \mathrm{~mL}$ of dry dichloromethane was then injected in the tube under magnetic stirring at $40{ }^{\circ} \mathrm{C}$ in nitrogen atmosphere. The reaction was quenched after $2 \mathrm{~h}$ by turning off the heating and adding methanol. The resulting solution was then concentrated under vacuum at room temperature, dissolved in acetonitrile and prepared for analysis. The protocol was the same for $Z$ - or $E$-PI with only modified ratios and temperature. For $25 \mathrm{mg}$ of polymer (Mw 38,000 g.mol $\left.{ }^{-1}, 0.657 \mu \mathrm{mol}\right), 10 \mu \mathrm{L}$ of chain transfer agent $([\mathrm{CTA}] /[\mathrm{PI}]=100)$ and $1.5 \mathrm{mg}$ of catalyst ([Catalyst $] /[\mathrm{PB}]=5$ ) were added and the mixture was heated at $50{ }^{\circ} \mathrm{C}$. Isomerization suppression. The cross-metathesis of $\mathrm{PB}$ and $\mathrm{PI}$ in both $Z$ - and $E$-configurations were performed under the same conditions as above with the addition of $10 \%$ (w/w of the polymer) of the 2,6-dichloro-1,4-benzoquinone as suppressor for olefin isomerization.

Mass spectrometry. All experimental details are given in supplementary information.

\section{RESULTS AND DISCUSSION}

In recent years, cross-metathesis has emerged as a very important method in polymer chemistry to form new carbon-carbon double bonds as it is based on the use of an organometallic catalyst which shows tolerance towards different functional groups. ${ }^{10,11}$ In most olefin metathesis reactions, the well-defined ruthenium carbene complexes $\mathbf{1}$ and $\mathbf{2}$ known as second-generation Grubbs and Hoveyda-Grubbs catalyst respectively are used. It is proven that complex $\mathbf{2}$ is more active than $\mathbf{1}$ however it introduces olefin isomerization as a side reaction. ${ }^{12}$

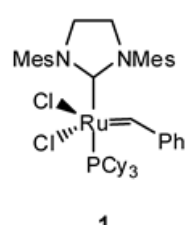

1

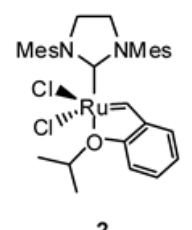

2

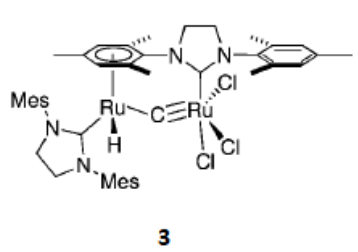

3
Figure 2. $2^{\text {nd }}$ generation Grubbs (1), $2^{\text {nd }}$ generation HoveydaGrubbs (2) catalysts and Ruthenium hydride species (3)

In recent years, PI recycling by cross-metathesis reaction using Grubbs or Hoveyda-Grubbs catalysts for the degradation of the $E$ - or Z-1,4-PI was carried out in various studies. The degradation of PI with molar mass between 35 and 116,000 g.mol ${ }^{-1}$ using the second generation Grubbs catalysts and Z-1,4-diacetoxy-2-butene as chain transfer agent (CTA) in ionic liquids, ${ }^{13}$ or by oxidizing it to dialdehyde or diacetal oligomers with periodic acid was decribed. ${ }^{14}$ In this work, we developed an analytical protocol for PB and PI depolymerization by cross-metathesis at low temperature (40 and $50{ }^{\circ} \mathrm{C}$ respectively) using the second generation Hoveyda-Grubbs catalyst and Z-1,4-acetoxy-2-butene as chain transfer agent (CTA) compatible with ESI ionization. As the reaction yielded a mixture of products formed of acetoxy telechelic polymeric oligomers soluble in organic solvents, ESI-MS was used to determine their $m / z$ ratios in order to give a precise structure and finger-print of each polymer. Unfortunately, the depolymerisation of these high molar mass polymers gives very complex mixtures and by consequence very complex mass spectra. However, this problem can be overcome by using high-resolution FT-ICR with resolving power of $1,000,000$ to efficiently separate very close peaks. First attempts of depolymerization were performed in dichloromethane using the second generation Hoveyda-Grubbs catalyst and the Z-1,4-diacetoxy-2-butene as chain transfer agent. ${ }^{15}$ This reaction was applied on PB and PI in both configurations as shown in Fig.3. The reaction was carried out in less than 1 hour for a fixed catalyst concentration of $1 \%$ (w/w of the polymer) and 5 equiv. of CTA. As expected, $M_{n}$ of PB decreased progressively from 200,000 to 250 until reaching a stable value even for a 10 minutes' reaction. The high activity of the catalyst is especially useful towards tri-substituted alkenes such as isoprene which are less reactive in cross-metathesis. ${ }^{16}$ As a result, this catalyst, proved to be very efficient for the depolymerization of PB and PI. High resolution mass spectra were recorded for both polymers and shown in Fig. 4. In the case of ( $E$ or $Z) \mathrm{PB}$ and PI, the major family of depolymerized fragments can be easily identified with a low $\mathrm{m} / \mathrm{z}$ error in the range of $10 \mathrm{ppb}$. For PB, signals separated by $54.0464 \mathrm{Da}$ in average corresponding to the repeating unit $\mathrm{C}_{4} \mathrm{H}_{6}$ present the highest intensity while in PI they 
are separated by 68. $0620 \mathrm{Da}$ corresponding to $\mathrm{C}_{5} \mathrm{H}_{8}$. However, much more signals appeared when narrowing the mass range of the spectrum. Molecular assignment of the large number of signals was realized using the FTMS visualization ( $i$-van Krevelen) open-source program written in Python. ${ }^{17}$ This software scans the mass spectrum and attributes molecular formulas taking into account the number of $\mathrm{CH}_{2}$, oxygen and unsaturation. More than 2000 signals for each polymer were assigned to molecular formulas from which more than 9 different families of molecules were identified. In the case of PB, the highest intensity signals correspond to the major family of oligomers $\left[\left(\mathrm{C}_{8} \mathrm{H}_{12}\right) \mathrm{O}_{4}+\left(\mathrm{C}_{4} \mathrm{H}_{6}\right)_{\mathrm{n}}+{ }^{7} \mathrm{Li}^{+}\right]$expanding from one monomer of PB at $m / z 233.1360\left(\mathrm{C}_{12} \mathrm{H}_{18} \mathrm{O}_{4}+{ }^{7} \mathrm{Li}^{+}\right)$up to 19 monomers at $m / z$ $1205.9812\left(\mathrm{C}_{84} \mathrm{H}_{126} \mathrm{O}_{4}+{ }^{7} \mathrm{Li}^{+}\right)$. Among the oligomers minority families, one is characterized by the presence of up to 4 additional oxygen atoms $\left[\left(\mathrm{C}_{8} \mathrm{H}_{12}\right) \mathrm{O}_{4}+\left(\mathrm{C}_{4} \mathrm{H}_{6}\right)_{\mathrm{n}}+\mathrm{O}_{\mathrm{m}}+{ }^{7} \mathrm{Li}^{+}\right]$and another by the increase in the number of double bonds $\left[\left(\mathrm{C}_{8} \mathrm{H}_{12}\right) \mathrm{O}_{4}\right.$ $\left.+\left(\mathrm{C}_{4} \mathrm{H}_{6}\right)_{\mathrm{n}}-\left(\mathrm{H}_{2}\right)_{\mathrm{p}}+{ }^{7} \mathrm{Li}^{+}\right]$. The last identified family, which can contain up to 10 monomers in total, consists of 3 PB chains reticulated by a $\mathrm{CH}$ group (Fig.5). These reticulated chains are a signature of the PB manufacturing process. ${ }^{18}$. Similarly for PI, the major family of oligomers with the highest intensity $\left[\left(\mathrm{C}_{8} \mathrm{H}_{12}\right) \mathrm{O}_{4}+\left(\mathrm{C}_{5} \mathrm{H}_{8}\right)_{\mathrm{n}}+{ }^{7} \mathrm{Li}^{+}\right]$expands from one monomer of PI at $\mathrm{m} / \mathrm{z} 247.1516\left(\mathrm{C}_{13} \mathrm{H}_{20} \mathrm{O}_{4}+{ }^{7} \mathrm{Li}^{+}\right)$up to 20 monomers at $\mathrm{m} / z$ $1540.3410\left(\mathrm{C}_{108} \mathrm{H}_{172} \mathrm{O}_{4}+{ }^{7} \mathrm{Li}^{+}\right)$. Additional lower intensity families are found in PI and characterized by the presence of up to 6 additional oxygen atoms $\left[\left(\mathrm{C}_{8} \mathrm{H}_{12}\right) \mathrm{O}_{4}+\left(\mathrm{C}_{5} \mathrm{H}_{8}\right)_{\mathrm{n}}+\mathrm{O}_{\mathrm{m}}+{ }^{7} \mathrm{Li}^{+}\right]$ and by the increase in the number of double bonds $\left[\left(\mathrm{C}_{8} \mathrm{H}_{12}\right) \mathrm{O}_{4}\right.$ $\left.+\left(\mathrm{C}_{5} \mathrm{H}_{8}\right)_{\mathrm{n}}-\left(\mathrm{H}_{2}\right)_{\mathrm{p}}+{ }^{7} \mathrm{Li}^{+}\right]$. Finally, a family with 4 reticulated chains of PI connected by one carbon atom was identified and can contain up to 8 monomers in total. (SI, Fig S1).
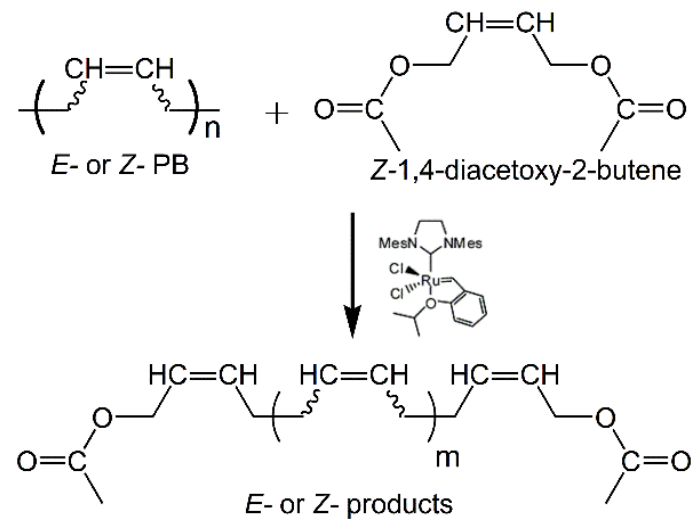

Figure 3. Cross-metathesis reaction of $E$ - and Z-PB in the presence of Z-1,4-diacetoxy-2-butene as chain transfer agent and the Hoveyda-Grubbs second generation catalyst (HGII).

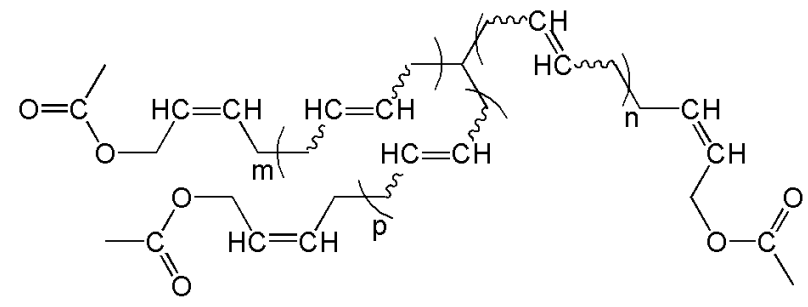

Figure 5. Identified family consisting of $3 \mathrm{~PB}$ chains reticulated by a $\mathrm{CH}$ group
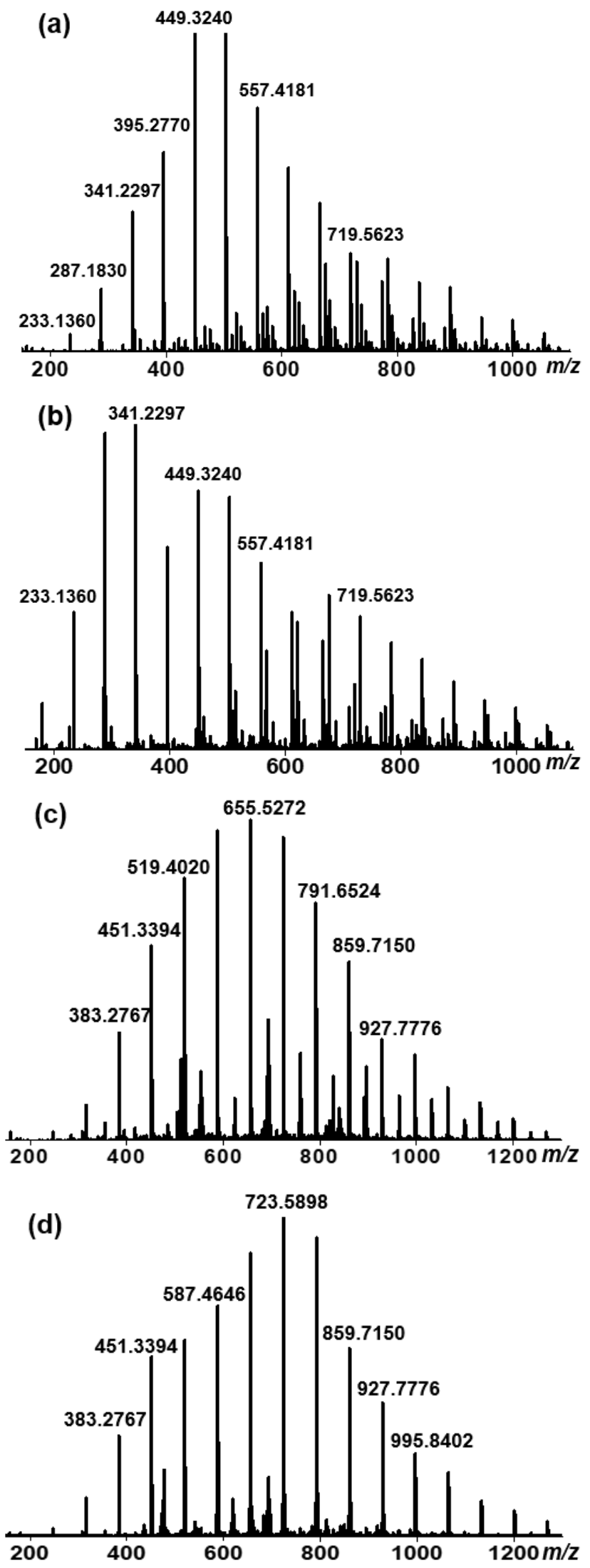

Figure 4. FT-ICR mass spectra of depolymerized (a) E-PB and (b) $Z$-PB (c) E-PI and (d) Z-PI in the presence of Z-1,4-diacetoxy-2butene and Hoveyda Grubbs second generation catalyst. 
However, ESI FT-ICR infusion did not provide information on the stereochemistry of the cross-metathesis oligomers which was studied by ion mobility spectrometry mass spectrometry (IMS-MS). In Figure 6a and 6c, drift times of $E$ - and Z-PB oligomer at $\mathrm{m} / z 395.2768$ show two peaks at 2.85 and $3.14 \mathrm{~ms}$, but unfortunately with the same $E / Z$ ratio (60/40). The other oligomers exhibit the same behavior. Grubbs suggested that isomerization can be suppressed by using moderate reducing agents such quinone-type compounds during olefin metathesis reactions. As isomerization is the result of the formation of ruthenium hydride species by the decomposition of the ruthenium metathesis catalysts, quinone-type compounds react with hydride species to produce hydroquinones and block the decomposition process. ${ }^{19}$ After optimization, analysis by IMS-MS of $E$ - and Z-PB oligomer at $\mathrm{m} / \mathrm{z} 395.2768$ confirmed the formation of only one major isomer by adding $10 \%$ (w/w of the polymer) of 2,6-dichloro-1,4-benzoquinone to the metathesis reaction. The major isomer has the same configuration as the starting polymer as shown in the $E / Z$ ratio in Figure $6 \mathrm{~b}$ and $6 \mathrm{~d}$. By comparing the drift times, $E$ - and $Z$-PB showed completely different times. In the case of $Z$-PB as starting polymer, two peaks were recorded at $3.02 \mathrm{~ms}$ ( $E$-isomer) and $3.22 \mathrm{~ms}$ ( $Z$-isomer), while for $E$-PB these two peaks were recorded at $2.93 \mathrm{~ms}$ ( $E$-isomer) and $3.20 \mathrm{~ms}$ ( $Z$-isomer). The same results were found in the case of $E$ - and Z-PI.
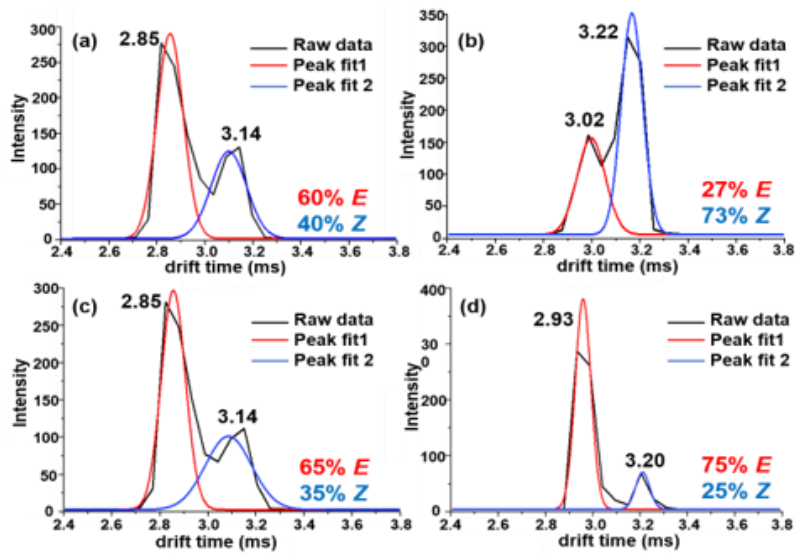

Figure 6. Ion mobility spectra extracted from the IM-MS data obtained from (a) depolymerized Z-PB, (b) depolymerized Z-PB after isomerization suppression, (c) depolymerized $E$-PB and (d) depolymerized $E$-PB after isomerization suppression. The black lines are experimental spectra extracted with a $\mathrm{m} / \mathrm{z}$ width of $0.01 \mathrm{Da}$. The red and blue signals were obtained from the deconvolution of the experimental profile with a Gaussian function.

Then, $E$ and $Z$ isomers were characterized by energy resolved MS/MS experiments (ERMS). ${ }^{20,21}$ The MS/MS spectrum of ion at $m / z 665.5147$ which corresponds to 9 monomers of PB shows two fragment at $\mathrm{m} / z, 605.4867$ corresponding to the loss of one acetyl group and at $m / z 545.4679$ corresponding the loss of two acetyl groups. Breakdown curves (Fig. 7) show that the product ion at $\mathrm{m} / \mathrm{z} 665.5147$ is fragmented in different patterns according to its configurations. The $Z$-isomer, is fragmented directly at low energy giving rise to its first product ion at $\mathrm{m} / \mathrm{z}, 605$ which reaches its highest abundance around $12 \mathrm{eV}$ and starts to fragment at its turn giving the product ion at $\mathrm{m} / \mathrm{z}, 545$ which starts to form at about $14 \mathrm{eV}$. In the case of the $E$-isomer, the $\mathrm{M}^{+}$is stable in the range between 0 to $8 \mathrm{eV}$ and starts to fragment at $10 \mathrm{eV}$ forming its first product ion at $\mathrm{m} / \mathrm{z}, 605$. This ion increases in intensity reaching its highest at $15 \mathrm{eV}$ where it also starts to dissociate and decrease giving rise to the smallest ion at $m / z 545$. Although less quantitative than IMS-MS, ERMS also proves the suppression of the isomerization during the cross-metathesis reaction was successful.

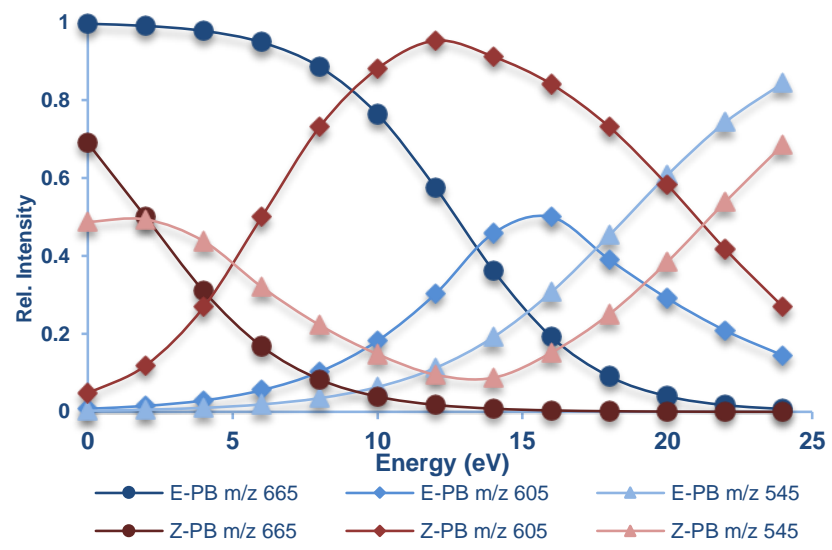

Figure 7 Breakdown curves obtained from the dissociation of $\left[\mathrm{M}+{ }^{7} \mathrm{Li}\right]^{+} 665.5147$ of $E$-PB and Z-PB

In order to demonstrate the potentialities of depolymerization FT-ICR MS and IMS for the analysis of polydienes, we compared it to classical MS methods based on pyrolysis. Previous studies showed that Py-GC/MS permitted to characterize the pyrolysis pattern of $\mathrm{PB}$ using polymers with various content ratio of $Z-1,4, E-1,4$ and 1,2-units and identified 13 gaseous products proving that $E$-butadiene oligomers are majorly produced. ${ }^{22}$ For all configurations the major pyrolysis products are $\mathrm{C}_{4} \mathrm{H}_{6}$ (butadiene), $\mathrm{C}_{5} \mathrm{H}_{8}$ (cyclopentene), $\mathrm{C}_{6} \mathrm{H}_{10}$ (cyclohexene), $\mathrm{C}_{7} \mathrm{H}_{10}$ (1,4-cycloheptadiene), and $\mathrm{C}_{8} \mathrm{H}_{12}$ (4-vinylcyclohexene). ${ }^{22-24} \mathrm{Py}-\mathrm{GC} \times \mathrm{GC} / \mathrm{MS}$ affords more information. (Figure 8 and 9).

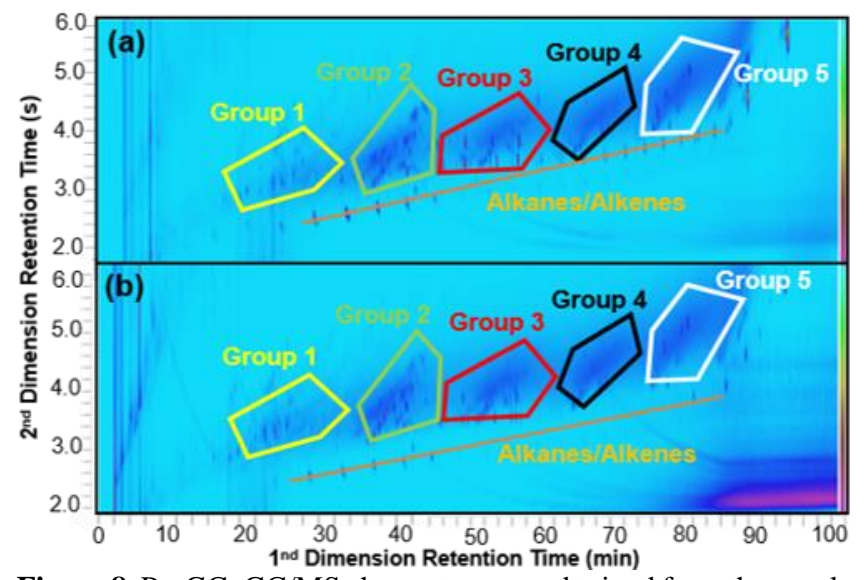

Figure 8. Py-GCxGC/MS chromatograms obtained from the pyrolysis of (a) E-PB and (b) Z-PB samples. The class of products observed are framed in different colors with the series of alkanes/alkenes in orange.

To fully determine the fingerprint of these polymers, assignment of the pyrolysis products was essential (SI, Table S1). For isomer identification the first region afforded the clearest pattern. Pyrolysis products $\mathrm{f} 1, \mathrm{f} 3$ and $\mathrm{f} 4$ exist in both configurations and correspond mostly to cyclic hydrocarbons. Product $\mathrm{f} 2$ is unique to Z-PB while products f5 and f6 are present only in the $E$ configuration of the polymer. In the second region extended between 31 and 48 minutes (SI, Fig. S2), both PB configurations present a similar product $\mathrm{f} 8$ while $\mathrm{f} 7$ is only found in $E$-PB. We can also notice that there are different parts of the chromatogram where the intensity of the pyrolysis products var- 
ies between $Z$ - and $E$-PB. For example, the red framed parts observed in both chromatograms contain the same products but with different intensities.

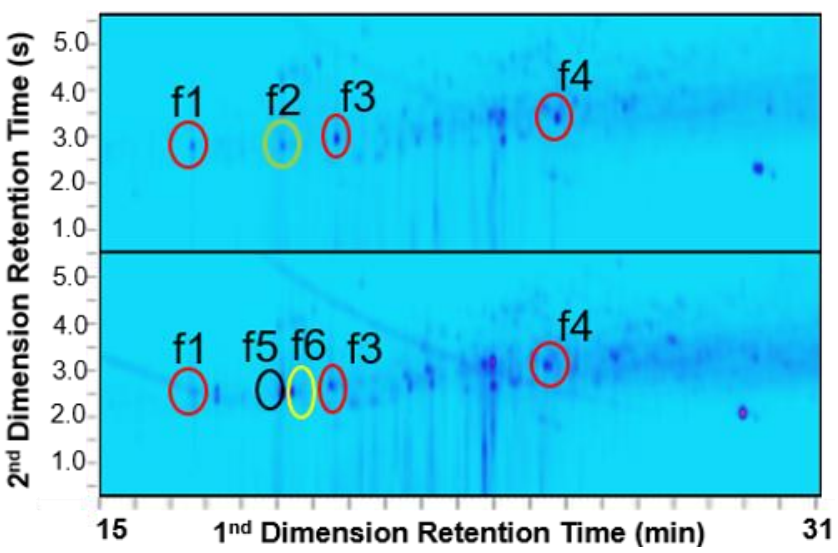

Figure 9. Expanded view of Py-GCxGC/MS of Z-PB (Up) and $E$-PB (Down) at the region of retention times in the first dimension: 15-31 minutes

For the analyzed $E$ and Z-PI, the same pattern found after the pyrolysis of PB can be observed (SI, Fig. S3). Chromatograms can be as well be divided into five major groups with the presence of additional products in the early region of retention time in the $1^{\text {st }}$ dimension (SI, Table 1). We can notice that products issued from the pyrolysis of PI started to appear at around 20 minutes of $1^{\text {st }}$ dimension retention time while in the case of $\mathrm{PB}$, first products appeared at 15 minutes. In the first group, low weight molecules can be identified and consisted mostly on polymerized short chains of isoprene such as dimers and trimers. We also noticed the presence on a series of alkenes similar to that found in PB. In the second group, longer polymerized chains of isoprene could be observed up to five isoprene units. In the higher retention time region, molecules became more difficult to assign however in the last three groups, differences between the $E$ and $Z$ configurations of PI were visible. The expansion of each region on the chromatogram allowed to observe that the products obtained after pyrolysis of these two polymers were very different. In the first part of the spectrum, extended between 20 and 41 minutes (SI, Fig. S4a), we can notice that both configurations have unique products at different retention times. For example, g4 exists only in Z-PI and may correspond to a low weight molecule. We can also observe some similarities especially close to 40 minutes. The same series of alkenes in also present in both cases. In the second part which starts at 41 minutes and ends around 62 minutes (SI, Fig. S4b), the same pattern can be observed. A high number of differences in addition to one clear similarity (g9) with variable intensity. Variations in the pyrolysis products according to the content of each polymer can be highly noted in the third and fourth region. In the third part of the chromatogram, we can see that almost every product present in E-PI is completely absent in Z-PI and the same is applied to the fourth part between 72 and 99 minutes (SI, Fig. S4c and S4d). This analysis definitely proves that $E$ and Z-PI rearrange in different patterns after pyrolysis depending on their microstructures. Analysis of inert PB and PI using pyrolysis uncovered valuable information and helped elucidate their structure.

Finally PB and PI in both $E$ and $Z$ configurations were then analyzed by atmospheric solid analysis probe coupled to ion mobility-mass spectrometry on a Q-TOF instrument (ASAP-MS)
(Figure 10). ${ }^{25,26}$ The initial analysis showed radical cation series separated by $54.04 \mathrm{Da}$ for $E$ - and Z-PB and $68.06 \mathrm{Da}$ for $E$ - and $Z$-PI, which correspond to $\mathrm{C}_{4} \mathrm{H}_{6}$ and $\mathrm{C}_{5} \mathrm{H}_{8}$ repeating units, respectively. Both $E$ - and $Z$-polymers yielded similar mass spectra. An expanded view for $E-P B$ and Z-PB (SI, Fig. S6a and S6b) allowed the identification of different ion distributions: I: $M_{w}=54.046 n ;$ II: $M_{w}=54.046 n+12.000$ (C); III: $M_{w}=54.046 n$ $+14.015\left(\mathrm{CH}_{2}\right) ; \mathrm{IV}: M_{w}=54.046 n+28.031\left(\mathrm{C}_{2} \mathrm{H}_{4}\right) ; \mathrm{V}: M_{w}=$ $54.046 n+40.031\left(\mathrm{C}_{3} \mathrm{H}_{4}\right)$; VI: $M_{w}=54.046 n+42.046\left(\mathrm{C}_{3} \mathrm{H}_{6}\right)$; VII: $M_{w}=54.046 n+15.994(\mathrm{O})$. Distribution I was detected as the most intense (90-95\%) and extended on the whole mass range. Distributions II, IV and VI are less intense with approximately similar relative intensities (30-35\%) followed by distribution III and V with the lowest intensity.

In the case of E-PI (SI, Fig S5c and S6c) and Z-PI (SI, Fig. S5d and S6d), the expanded view allowed the identification of the following distributions: I: $M_{w}=68.062 n$; II: $M_{w}=68.062 n+$ 12.000; III: $M_{w}=68.062 n+14.015\left(\mathrm{CH}_{2}\right)$; IV: $M_{w}=68.062 n+$ $28.031\left(\mathrm{C}_{2} \mathrm{H}_{4}\right) ; \mathrm{V}: M_{w}=68.062 n+40.031 ; \mathrm{VI}: M_{w}=68.062 n+$ 42.046 ( $\left.\mathrm{C}_{3} \mathrm{H}_{6}\right)$; VII: $M_{w}=68.062 n+56.062\left(\mathrm{C}_{4} \mathrm{H}_{8}\right)$; VIII: $M_{w}=$ $68.062 n+15.994(\mathrm{O})$. Distribution I was detected with the highest intensity at $90 \%$ and extended on the entire mass range. Distributions II and V followed with lower intensity (10-30\%) and finally distributions III and IV had the lowest intensity. Several additional distributions with low intensities may be explained by in source fragmentation originating from the main distributions. ASAP is an energetic ionization source which is known to induce this type of fragmentations. ${ }^{27}$ Ion mobilitymass spectrometry data did not show any differences between the two configurations of each polymer. This is presumbly due to the formation of cyclic compounds from the low temperature pyrolysis. $^{28-30}$

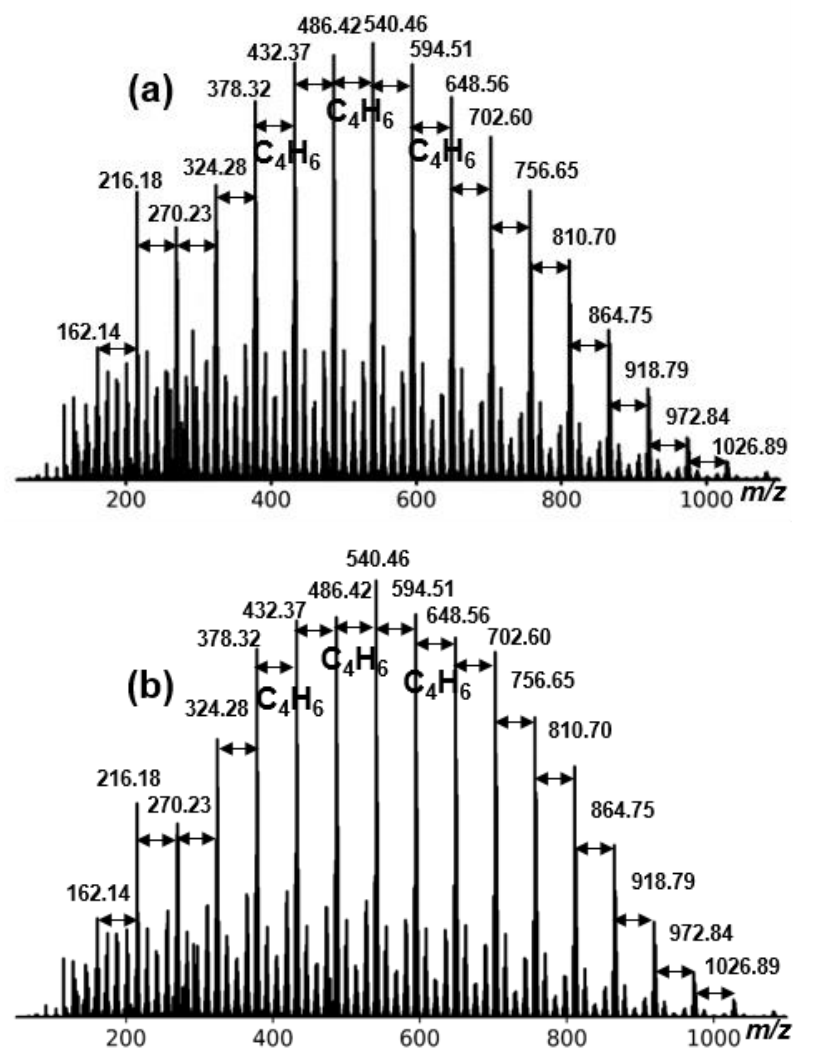

Figure 10. ASAP-MS results of $P B$ samples. The extracted mass spectra obtained for: (a) E-PB, (b) Z-PB showing ion series separated by $54.0464 \mathrm{Da}\left(\mathrm{C}_{4} \mathrm{H}_{6}\right)$ 
For both $E$ - and Z-PB (Fig. 11a and 11b), both plots present one diagonal with the same ion distributions. We can also notice the presence of the different distributions mentioned above and especially distributions I, II, III and IV. In the case of PI, E-PI presents two diagonals (SI, Fig. S7c). The diagonal with the higher slope corresponds to ions having the highest drift times and these are attributed to the distributions mentioned above with distribution I having the highest intensity. The diagonal with the lower slope corresponds to a family of poly(ethylene glycol) (PEG). In fact, $E$-PI is commercially available as pellets and PEG is used as a plasticizer. ${ }^{31}$ However, for Z-PI only one diagonal is present and corresponds to the same ion distributions found in E-PI (distributions I, II, II, IV and V) (SI, Fig. S7d).

ASAP-MS helped uncover most of the species issued from pyrolysis of both PB and PI, however, analysis of complex mixtures requires higher-resolution. As expected the ASAP spectra on a Q-TOF instrument and the DIP-APCI spectra are similar at a first glance showing ions ion series issued from the pyrolysis of $E$-and $Z$ - $P B$ separated by $54.0464 \mathrm{Da}$ corresponding to one $\mathrm{C}_{4} \mathrm{H}_{6}$ monomer (SI, Fig. S8a and S8b) while ion series of $E$ - and Z- PI were separated by $68.0620 \mathrm{Da}$ corresponds to the monomer $\mathrm{C}_{6} \mathrm{H}_{8}$ (SI, Fig. S8c and S8d). In the case of $\mathrm{PB}$, the first intense peak at $\mathrm{m} / \mathrm{z}, 530$ can be attributed to the molecular ion of an antioxidant, Irganox $1076\left(\mathrm{C}_{35} \mathrm{H}_{62} \mathrm{O}_{3}\right){ }^{32}$ When mass spectra were analyzed in details they showed an overlap between different peaks with the same nominal mass (Fig. 12a). ${ }^{13} \mathrm{C}$ isotope of radical cation $\mathrm{M}^{+}$. may be clearly identified from the protonated ion $[\mathrm{M}+\mathrm{H}]^{+}$. For example, the peak at $m / z, 540.4639$ corresponds to the $\mathrm{C}_{40} \mathrm{H}_{60}$ cation radical. The signal at +1 Da separated into two peaks: the first one at $\mathrm{m} / \mathrm{z}$ 541.4724 corresponds to radical cation $\mathrm{M}^{+}$.with one ${ }^{13} \mathrm{C}$ isotope $\left({ }^{13} \mathrm{C}_{1}{ }^{12} \mathrm{C}_{39} \mathrm{H}_{60}\right)$ while the second peak at $\mathrm{m} / z, 541.4768$ corresponds to the protonated species with $\mathrm{C}_{40} \mathrm{H}_{61}\left[\mathrm{M}+\mathrm{H}^{+}\right]$(Fig. $12 \mathrm{~b})$. So, DIP-APCI and presumably also ASAP affords of mixture of radical cation which dominates and cation.
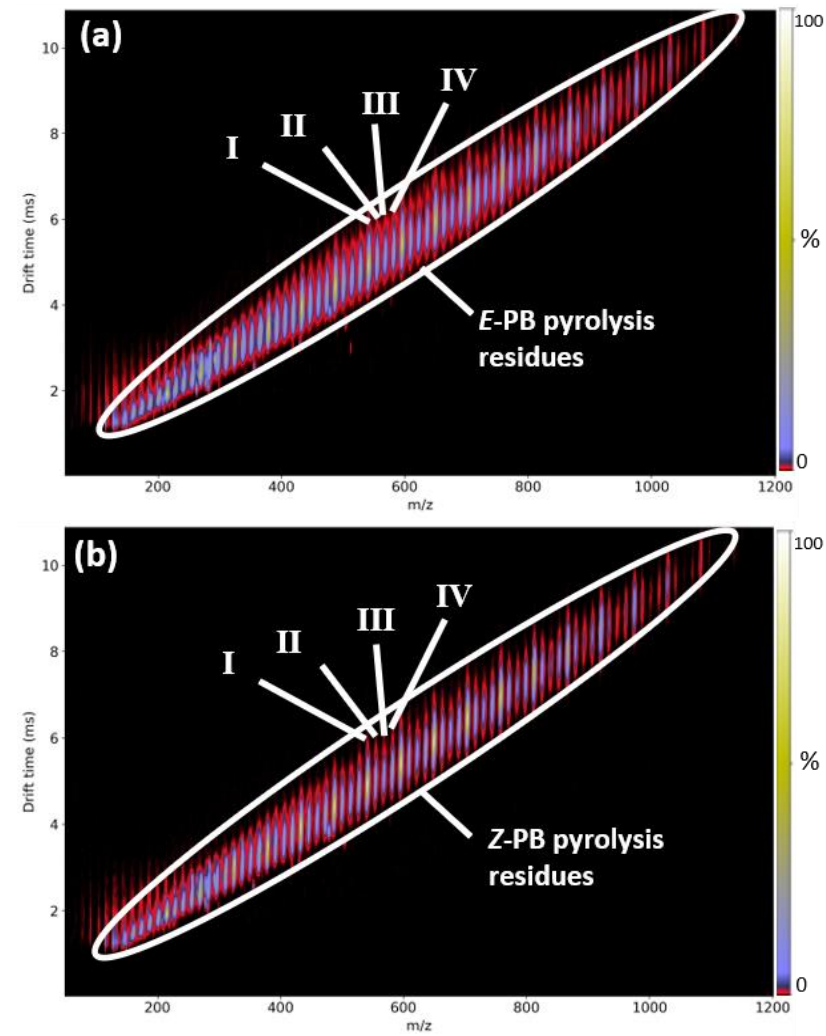

Figure 11. ASAP-MS results of PB: $m / z$-drift time plot respectively for (a) E-PB and (b) Z-PB
The DIP-APCI source produces also slightly more products than the ASAP source. For example, for $E$ - and Z-PB, the species $\mathrm{C}_{40} \mathrm{H}_{60} \mathrm{~m} / z 540.4688$ is also present with the addition from one to four oxygen atoms at $m / z, 556.4638 \mathrm{C}_{40} \mathrm{H}_{60} \mathrm{O}$ up to $\mathrm{m} / z$ $604.4487 \mathrm{C}_{40} \mathrm{H}_{60} \mathrm{O}_{4}$ with four additional oxygen atoms (Fig. 12c). In addition, the peak at $m / z 556.4641$ is accompanied by a peak $m / z, 556.5003$ corresponding to $\mathrm{C}_{40} \mathrm{H}_{60} \mathrm{~m} / z, 540.4690$ plus $\mathrm{CH}_{4}$ or $m / z 542.4846\left(\mathrm{C}_{40} \mathrm{H}_{62}\right)$ plus one $\mathrm{CH}_{2}$, giving $\mathrm{C}_{41} \mathrm{H}_{64}$ as molecular formula (Fig. 11c). The same kind of attribution can be made for for $E$ - and Z-PI (SI, Fig. S9). The nominal mass $m / z$ 560 , can also be separated into different species. The first peak at $m / z 560.4995$ corresponds to $m / z, 544.5002\left(\mathrm{C}_{40} \mathrm{H}_{64}\right)$ plus one atom of oxygen $\left(\mathrm{C}_{40} \mathrm{H}_{64} \mathrm{O}\right)$. The second peak with $\mathrm{m} / z$ 560.5315 corresponds to $\mathrm{m} / z .546 .5159\left(\mathrm{C}_{40} \mathrm{H}_{66}\right)$ plus one $\mathrm{CH}_{2}$ molecule $\left(\mathrm{C}_{41} \mathrm{H}_{68}\right)$. It should be pointed out that this behavior is displayed as a continuous distribution at each nominal $\mathrm{m} / \mathrm{z}$ value.
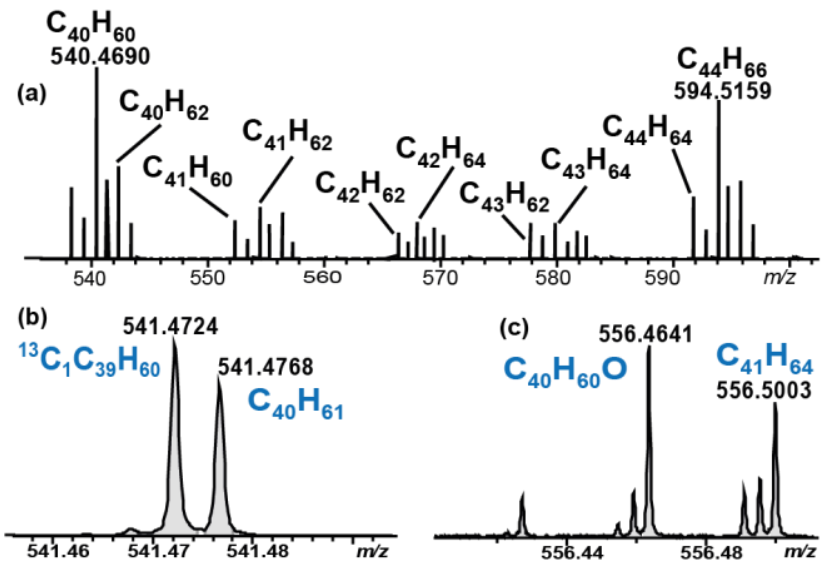

Figure 12. (a) Distribution of ions between $\mathrm{m} / \mathrm{z} 540$ and $600 \mathrm{ob}-$ tained from DIP-APCI-FTICR analysis of PB and expansion of the DIP-APCI-FTICR spectrum of PB at the nominal mass (b) $\mathrm{m} / \mathrm{z} 541$ and (c) $\mathrm{m} / z, 556$ showing different identified species.

\section{CONCLUSION}

In summary, this work presents the first detailed investigation of polybutadiene and polyisoprene in $E$ and $Z$ configurations, by a new approach based on a metathesis reaction for obtaining end-functionalized oligomers easily ionizable by ESI. IMS showed that oligomers isomerize during the reaction affording mixtures of products similar for $E$ and $Z$ isomers. Improved catalytic conditions led to suppressing the isomerization IMS demonstrated that the stereochemistry is well preserved. Additional experiments using ERMS proved differences in the fragmentation patterns of isomers and the success of preventing isomerization. Slow pyrolysis by ASAP or DIP-APCI coupled to respectively IMS-MS or FTICR-MS gave species with identical $m / z$ values in the case of PB and PI. The existence of several ionization processes leading to pronated species or radical cation was proved by high resolution FTICR MS. On the other hand, analysis by GC $\times$ GC-MS of the PB and PI samples gave clearly visible peaks specific to $E$ and $Z$. Further experiments on more complex natural polymers with isoprene units are currently in progress in order to try and identify the detailed structures of these macromolecules.

\section{ASSOCIATED CONTENT}

\section{Supporting Information}

The Supporting Information is available free of charge on the ACS Publications website. 


\section{AUTHOR INFORMATION}

\section{Corresponding Author}

*Christian Rolando - Univ. Lille, CNRS, USR 3290, MSAP, Miniaturisation pour la Synthèse l'Analyse et la Protéomique, F-59000 Lille, France ; Email : christian.rolando@univ-lille.fr; orcid.org/0000-0002-3266-8860

\section{Authors}

Ziad Mahmoud - Univ. Lille, CNRS, USR 3290, MSAP, Miniaturisation pour la Synthèse l'Analyse et la Protéomique, F-59000 Lille, France ; orcid.org/0000-0002-5563-0558

Fabrice Bray - Univ. Lille, CNRS, USR 3290, MSAP, Miniaturisation pour la Synthèse l'Analyse et la Protéomique, F-59 000 Lille, France ; orcid.org/ 0000-0002-4723-8206

Marie Hubert-Roux - Normandie Université, Université de Rouen, UMR 6014, CNRS, COBRA, Chimie organique et bioorganique, Réactivité et Analyse, 76821 Mont-Saint-Aignan Cedex, France ; orcid.org/ 0000-0003-4986-4590

Michel Sablier - Muséum National d'Histoire Naturelle, USR 3224, CNRS, Centre de Recherche sur la Conservation, 36, rue Geoffroy Saint-Hilaire, 75005 Paris ; orcid.org/ 0000-0001-6508$\underline{8566}$

Carlos Afonso - Normandie Université, Université de Rouen, UMR 6014, CNRS, COBRA, Chimie organique et bioorganique, Réactivité et Analyse, 76821 Mont-Saint-Aignan Cedex, France ; orcid.org/ 000-0002-2406-5664

\section{Author Contributions}

The manuscript was written through contributions of all authors and all authors have given approval to the final version of the manuscript.

\section{Note}

The authors declare no competing financial interest.

\section{ACKNOWLEDGMENT}

The Mass Spectrometry facilities used in this study were funded by the EU European Regional Development Fund (ERDF), Region Haut de France (France), the CNRS, and the Universite de Lille. Access to the FT-ICR MS in the frame of the EU_FTICR_MS network installation funded by the EU Horizon 2020 grant 731077 and support for conducting research is gratefully acknowledged.

\section{REFERENCES}

(1) Crotty, S.; Gerişlioğlu, S.; Endres, K. J.; Wesdemiotis, C.; Schubert, U. S. Anal. Chim. Acta 2016, 932, 1-21.

(2) Hanton, S. D. Chem. Rev. 2001, 101, 527-570

(3) Peter, K. Pyrolysis-gas Chromatography: Mass Spectrometry Of Polymeric Materials; World Scientific, 2018.

(4) McEwen, C. N.; McKay, R. G.; Larsen, B. S. Anal. Chem. 2005, 77, 7826-7831.

(5) McEwen, C. N. In Encyclopedia of Analytical Chemistry; American Cancer Society, 2010.

(6) Li, L. MALDI Mass Spectrometry for Synthetic Polymer Analysis; Wiley, 2009

(7) Whitson, S. E.; Erdodi, G.; Kennedy, J. P.; Lattimer, R. P.; Wesdemiotis, C. Anal. Chem. 2008, 80, 7778-7785.

(8) Lattimer, R. P.; Polce, M. J. J. Anal. Appl. Pyrolysis 2011, 92, 355-360.

(9) Hunt, S. M. 1996.

(10) Dong, Y.; Matson, J. B.; Edgar, K. J. Biomacromolecules 2017, 18 1661-1676.

(11) Grubbs, R. H. Tetrahedron 2004, 60, 7117-7140.

(12) Grubbs, R. H. Angew. Chem. Int. Ed. Engl. 2006, 45, 3760-3765.

(13) Mouawia, A.; Nourry, A.; Gaumont, A.-C.; Pilard, J.-F.; Dez, I. ACS

Sustain. Chem. Eng. 2017, 5, 696-700.
(14) Berto, P.; Grelier, S.; Peruch, F. Polym. Degrad. Stab. 2018, 154, 295 -303 .

(15) Solanky, S. S.; Campistron, I.; Laguerre, A.; Pilard, J.-F. Macromol. Chem. Phys. 2005, 206, 1057-1063.

(16) Stewart, I. C.; Douglas, C. J.; Grubbs, R. H. Org. Lett. 2008, 10, 441444

(17) Kew, W.; Blackburn, J. W. T.; Clarke, D. J.; Uhrín, D. Rapid Commun. Mass Spectrom. 2017, 31, 658-662.

(18) Forens, A.; Roos, K.; Dire, C.; Gadenne, B.; Carlotti, S. Polymer 2018, $153,103-122$.

(19) Hong, S. H.; Sanders, D. P.; Lee, C. W.; Grubbs, R. H. J. Am. Chem. Soc. 2005, 127, 17160-17161.

(20) McLuckey, S. A.; Sallans, L.; Cody, R. B.; Burnier, R. C.; Verma, S.; Freiser, B. S.; Cooks, R. G. Int. J. Mass Spectrom. Ion Phys. 1982, 44, 215 $-229$.

(21) Fetterolf, D. D.; Yost, R. A. Int. J. Mass Spectrom. Ion Phys. 1982, 44, $37-50$.

(22) Arisawa, H.; Brill, T. B. Combust. Flame 1996, 106, 131-143.

(23) Ganesh, K.; Sundarrajan, S.; Kishore, K.; Ninan, K. N.; George, B.; Surianarayanan, M. Macromolecules 2000, 33, 326-330.

(24) Radhakrishnan, T. S.; Rao, M. R. J. Polym. Sci., Polym. Chem. Ed. 1981, 19, 3197-3208.

(25) Barrère, C.; Maire, F.; Afonso, C.; Giusti, P. Anal. Chem. 2012, 84, 9349-9354.

(26) Trimpin, S.; Inutan, E. D.; Karki, S.; Elia, E. A.; Zhang, W.-J.; Weidner, S. M.; Marshall, D. D.; Hoang, K.; Lee, C.; Davis, E. T. J. Am. Soc. Mass Spectrom. 2019, 30, 1133-1147.

(27) Smith, M. J. P.; Cameron, N. R.; Mosely, J. A. Analyst 2012, 137, 4524-4530.

(28) Golub, M. A.; Gargiulo, R. J. Journal of Polymer Science Part B: Polymer Letters 1972, 10, 41-49.

(29) Chen, F.; Qian, J. Fuel Process. Technol. 2000, 67, 53 - 60.

(30) Chen, F.; Qian, J. Fuel 2002, 81, 2071-2077.

(31) Domján, A.; Bajdik, J.; Pintye-Hódi, K. Macromolecules 2009, 42 , 4667-4673.

(32) Wang, F. C.-Y. J. Chromatogr. A 2000, 891, 325 - 336. 